\title{
Mais (e melhores) Médicos
}

Ana Maria COSTA

Sábado Nicolau GIRARDI ${ }^{2}$

Vinicius Ximenes Muricy da ROCHA ${ }^{3}$

Erika Rodrigues de ALMEIDA ${ }^{4}$

Leonor Maria Pacheco SANTOS ${ }^{5}$

\section{INTRODUÇÃO}

Em um primeiro plano, é imprescindível reafirmar que a assistência à saúde depende diretamente dos trabalhadores deste setor e da capacidade dos mesmos para a produção do cuidado. Mesmo considerando que hoje a medicina e a atenção à saúde estão impregnados por noções que supervalorizam as máquinas, os exames e as tecnologias duras, é necessário enfatizar que saúde se faz com e para as pessoas, sendo determinante a atuação dosprofissionais de saúde para se estabelecer o sucesso de um modelo de atenção.

Também deve ser pontuado que há deficiências, quantitativas e qualitativas, na formação de diversas profissões da saúde no Brasil, e que estas profissões são fundamentais na constituição da equipe para uma atençãointegral. A equipe de saúde deve ofertar um cuidado abrangente, ser resolutiva e capaz de atender o maior volume dos problemas de saúde apresentados pela população de um determinadoterritório. É por esta razão que as equipes devem ser suficientes, qualificadas e bem distribuídas, efetivando o acesso universal da população residente em toda a extensão do país, nos moldes definidos para o direito constitucional dos brasileiros. Háevidências suficientes na literatura que mostram o tamanho desse desafio e o drama dos gestores municipais quanto ao provimento dos profissionais, com claro destaque sobre maiores dificuldades em relação aos médicos.

Estudo sobre a força de trabalho em medicina, enfermagem e odontologia apontou que entre 2000 e 2010 o número de médicos apresentou crescimento próximo ao observado para o total da economia, de 3\% ao ano, e bem inferior ao crescimento do mercado no setor saúde. Este setor engloba os serviços de saúde propriamente ditos, atividades de produção e distribuição de fármacos, vacinas e medicamentos para uso humano; produção de insumos e equipamentos para o

\footnotetext{
1 Professora no Curso de Medicina da Escola Superior de Ciências da Saúde do Distrito Federal, ESCS. Ex- Presidenta do Centro Brasileiro de Estudos de Saúde, CEBES.

2 Coordenador da Estação de Pesquisa de Sinais de Mercado/ Observatório de Recursos Humanos em Saúde da UFMG, Membro do Grupo deEspecialistas da Organização Mundial da Saúde para aumento do acesso aos trabalhadores de saúde em áreas remotas.

3 Médico de Família e Comunidadee Sanitarista, professor da Universidade Federal de Campina Grande.

4 Sanitarista, Gestora de Políticas Públicas de Saúde.

5 Patologista, Chefe do Departamento de Saúde Coletiva da UNB.
} 
setor; atividades de ensino, pesquisa e desenvolvimento; atividades de planos de saúde; atividades de saneamento e a gestão governamental dos serviços de saúde ${ }^{1}$.

Para a população, tal como mostrou a pesquisa do Instituto de Pesquisa Econômica Aplicada (IPEA), o principal problema do Sistema Único de Saúde (SUS) para os usuários é a falta de médicos ${ }^{2}$. Mesmo discordando dessa assertiva, que localiza exclusivamente na falta destes profissionaiso principal problema da saúde,é preciso reconhecer o que mostram diversos estudos ${ }^{3,4,5}$ : faltam médicos no Brasil e esta falta ocorre principalmente no setor público do sistema de saúde.

Por outro lado, seria falacioso afirmar que o principal problema do SUS é a falta de médicos. Na verdade, este é mais um dos sintomas do descaso crônico na implantação doSUS, que vem sendo relegado, pelos sucessivos governos no período pós-constitucional, a ser um sistema de baixa qualidade para atendimento da população pobre que não pode pagar a saúde suplementar.

É preciso analisar as razões pelas quais os médicos não se vinculam ao SUS e não ocupam o vasto vazio geográfico destes profissionais. Nesse sentido, o argumento de que são apenas as más condições de estrutura e trabalho que explicam a ausência de médicos no SUS talvez não seja suficiente para a elucidação do problema. Isso só poderia ser verdade se existisse um contingente de médicos desempregados por recusa de condições insuficientes,o que não existe, segundo as pesquisas. Ao contrário,praticamente todos os médicos brasileiros possuem um ou mais empregos,inclusive com carga horária semanal que ultrapassa 40 horas, como evidencia recente pesquisa do IPEA $^{6}$.

\section{Perspectivas para a formaçãomédica com o Programa Mais Médicos}

A carência e má distribuição dos profissionais médicos têm sido temas amplamente demonstrados. Em virtude disso, em janeiro de 2013 a Frente Nacional dos Prefeitos do Brasil lançou a campanha “Cadê o médico?”,reivindicando do Governo Federal a contratação de médicos estrangeiros para atuar em municípios onde havia escassez ${ }^{7}$. Em resposta,o Programa Mais Médicos foi criado por Medida Provisória em julho de 2013, convertida naLei12.871, em 22 de outubro de 2013. O programa elegeu três frentes estratégicas: (i) qualificação profissional, com abertura de vagas em Cursos de Medicina orientados por novas Diretrizes Curriculares Nacionais; (ii) investimentos na construção e melhoria na infraestrutura de Unidades Básicas de Saúde; e (iii) provimento de médicos brasileiros e estrangeiros em municípios com áreas de maior vulnerabilidade.

A argumentação em oposição ao Programa Mais Médicos, sustentada especialmente pelas entidades médicas, está baseada na suficiência de médicos, desconhecendo o conjunto de estudos que mostram existir deficiência e má distribuição destes profissionais, caracterizado por sua extensão como um problema grave. Associações de classe impetraram duas Ações Diretas 
de Inconstitucionalidade (ADIn) contra o Programa, questionando, entre outros aspectos, a ausência de requisitos de relevância e urgência ${ }^{8}$. Ospareceres da Câmara dos Deputados, Senado Federal, Presidência da República, Advocacia-Geral da União e Procuradoria-Geral da República argumentaram que o Programa não transgrediu normativamente os preceitos constitucionais. As ADInsainda permanecemem julgamento no Supremo Tribunal Federal eambos os processos encontram-se conclusos ao Ministro Relator, aguardando decisão ${ }^{8}$.

O Brasil adiou, durante muitos anos, o enfrentamento dessa questão, e caso não tivesse lançado o Programa Mais Médicospersistiriam as injustas desigualdades regionais de acesso de estudantes a cursos de Medicina.As evidências indicam e a Organização Mundial de Saúde (OMS) recomenda a interiorização da oferta de escolas médicas como estratégia de ampliar as chances de fixação dos profissionais em áreas rurais, periféricas e remotas 9 .

Estudossobre a força de trabalho em medicina, enfermagem e odontologia já citados ${ }^{1}$, mostraram que durante o período compreendido entre 1991 e 2012 houve aumento de vagas para os três cursos no país e foram criadas 10.145 vagas em Medicina, o que representou um incremento bruto de $229 \%$. No entanto, os dados apontaram que no caso de Enfermagem e Odontologia,a oferta de vagas foi superior à procura, em contraponto, nos cursos de Medicina o aumento da oferta esteve sempre acompanhado pela demanda correspondente, não havendo desperdício ${ }^{1}$.

Adicionalmente, apesar de haver mais de 250 escolas médicas no Brasil, a quantidade de vagas em cursos de Medicina por 10 mil habitantes nopaís está bem abaixo de vários outros países com sistemas públicos e universais de saúde. Tínhamos, em 2011, 0,8 vagas para cada 10 mil habitantes. Em relação a ingressantes, também estamos aquém. O Reino Unido, por exemplo, já tinha, no mesmo período,uma relação de 1,61 para 10 mil habitantes, com uma quantidade de escolas médicas bem inferior à nossa ${ }^{10}$.

É preciso também considerar uma forte desigualdade regional na distribuição de vagas de graduação e residência em Medicina, com as regiões Norte, Nordeste e Centro-Oeste com uma desproporção de vagas enorme em relação ao Sul e Sudeste do país. E mesmo nestas duas últimas regiões, observa-se uma distribuição extremamente irregular dentro de seus territórios estaduais.

Neste sentido, junto àimplantação denovos cursos de Medicina contemplandolocorregiões com dificuldade para provimento de médicos, deve estar associadatambém a abertura, na mesma proporção, de vagas de residência médica, principalmente na área de Medicina Geral de Família e Comunidade e mais duas outras áreas básicas (Clínica Médica, Pediatria, Ginecologia e Obstetrícia, Cirurgia Geral e Medicina Preventiva e Social). Estas medidas, oportunizadas a jovens destas localidades, potencializam a fixação de profissionais médicos ${ }^{9}$. Além disso, hospitais conveniados vinculados ao SUS, que são campos de prática para estes cursos, podem pleitear a certificação 
como hospitais de ensino, política que contribui para incentivos financeiros a estes serviços.

Este modelo de cursos de medicina regionalizados, como os propostos pelas universidades de Western Ontário, no Canadá, James Cook, na Austrália e Walter Sisulu,na África do Sul,seguem parâmetros internacionais preconizados por importantes autoridades da discussão sobre a educação médica mundial. Há um consenso entre estudiosos desta área quanto à necessidade de mudanças na formação,proporcionando médicos mais próximos e habilitados ao cuidado integral e à resolução dos problemas mais prevalentes na população. É preciso desenvolver atitudes, habilidades e conhecimentos para serem bons médicos generalistas, antes de serem eventualmente bons especialistas. Assim, vêm sendo experimentadas propostas de inovação curricularem diversos países, incluindo pesquisadores da Universidade de Harvard que afirmam que se vivencia um momento de uma nova geração de reformas na educação médica mundial, na qual os cursos de Medicina podem prescindir do hospital universitário, com enfoque na atenção terciária. Esta proposta crítica substitui o aprendizado focado principalmente nas doenças raras e em procedimentos baseados essencialmente na alta tecnologia ${ }^{11}$.

No âmbito do Programa Mais Médicos, estão previstas mais 11.447 vagas em cursos de graduação em Medicina, sendo 3.615 vagas previstas em Instituições Federais de Educação Superior (IFES), através tanto do aumento de vagas em cursos existentes como a abertura de 38 novos cursos, exclusivamente em áreas interioranas, como o semiárido nordestino, Vales do Jequitinhonha e Mucuri, Baixada Maranhense, Amazônia Legal, Contestado Catarinense, Pampa Gaúcho, novas áreas agrícolas e regiões de fronteira no Cone-Sul ${ }^{12}$.

Estes cursos, além de uma orientação do ensino baseado na comunidade e fortemente pautados pela integração ensino-serviço, buscam metodologias problematizadoras para a formação médica e vêm experimentando mecanismos de valorização de ingresso para estudantes pobres e das camadas médias dessas regiões historicamente marginalizadas pelas políticas públicas. Alguns destes cursos têm oportunizado o acesso à graduação em Medicina por meio de processos seletivos que consideram argumentos de inclusão regional, complementarmente à Lei de Cotas.

É mister que processos inclusivos desta magnitude não podem descuidar de aspectos relacionados à gestão da qualidade. Neste sentido, o aperfeiçoamento do Sistema Nacional de Avaliação da Educação Superior (SINAES), com melhoria de seus processos de avaliação externa, sinergicamente articulados com avaliações bianuais progressivas dos estudantes de Medicina e acompanhamento permanente dos novos cursos nas IFES, através de especialistas em educação médica que compõem a Comissão de Acompanhamento e Monitoramento das Escolas Médicas (CAMEM), induzem a implementaçãodesse novo parâmetro internacional de qualidade na formação médica não apenas nos novos cursos de Medicina, mas alcançando também os cursos tradicionais. 
Sobre o acesso aos cursosde Medicina,pesquisas realizadas por especialistas em educação sobre uma análise do perfil socioeconômico do estudante de graduação, tanto em instituições públicas como privadas, vêm mostrando que políticas como PROUNI, PROIES, SISU, FIES, Lei de Cotas, PNAES e outras vêm garantindo, mesmo nos cursos de Medicina, um perfil menos branco e com menor proporção de estudantes de famílias de alta renda.Entretanto, estas evidências indicam que, no caso da Medicina, o Brasil ainda está aquém dos avanços de inclusão social observados em outros cursos de educação superior ${ }^{13}$. O Programa Mais Médicos vem para enfrentar estes desafios, diante de uma importante agenda de inclusão social e regional.

Talvez este seja o fator de maior reação por parte dos setores organizados enquanto corporação, na categoria médica, que criticam impiedosamente a nova política: uma possível mudança do perfil do estudante de Medicina, diante de uma maior oportunidade a jovens de várias camadas sociais ingressarem nestes cursos, diversificando, assim, a composição dos mesmos.

Reação que é, no mínimo, injustificada, pois além de não haver horizonte de saturação do mercado de trabalho da profissão a médio e longo prazo, estes setores da sociedade de onde predominantemente vem a corporação médica continuarão presentes, mantendo a oportunidade de seus filhos estarem nesses cursos. A perspectiva de mudança é que este segmento da sociedade não terá mais a exclusividade de acesso à formação médica, como praticamente tinha até então.

Assim, diversificando-se socialmente os cursos de Medicina e constituindo um perfil de formação médica que valorize a Clínica Geral, denominada no Brasil de Medicina (Geral) de Família e Comunidade, como a base fundamental para a prática da Medicina, poderemos garantir não só mais, como melhores médicos para o país.

\section{REFERÊNCIAS BIBLIOGRÁFICAS}

1. WAN DER MAAS L, CARVALHO CL, PIERANTONI CR, GIRARDI SN. Estrutura atual e estimativas futuras da força de trabalho em medicina, enfermagem e odontologia no Brasil 2000 a 2030. Saúde Amanhã; Textos para Discussão No 6. Rio de Janeiro: Fundação Oswaldo Cruz, 2015. [Acesso em 29 dez 2015] Disponível em: http://saudeamanha.fiocruz.br/sites/ saudeamanha.fiocruz.br/files/SA\%20-\%20TD\%2006.pdf

2. BRASIL. IPEA Instituto de Pesquisa Econômica Aplicada. O Sistema de Indicadores de Percepção Social. Brasília: IPEA, 2011. [Acesso em 29 dez 2015] Disponível: http://www.ipea. gov.br/portal/images/stories/PDFs/SIPS/110207_sipssaude.pdf

3.ATTAL-TOUBERT K, VANDERSCHELDEN M. La démographiemédicale à l'horizon 2030: de nouvellesprojectionsnationalesetrégionales. EtudRésult; (679). 2009 [Acesso em 29 Dez 2015]. Disponível em: http://www.drees.sante.gouv.fr/la-demographie-medicale-a-l-horizon- 
2030-de-nouvelles-projections-nationales-et-regionales-detaillees, $5488 . \mathrm{html}$

4. CARVALHO MS, SOUSA MF. Como o Brasil tem enfrentado o tema provimento de médicos? Interface (Botucatu) 2013;17(47):913-26. [Acesso em 29 Dez 2015] Disponível em: http://dx.doi.org/10.1590/1807-57622013.0403

\section{OLIVEIRA FP, VANNI T, PINTO HA, SANTOS JTR, FIGUEIREDO AM, ARAÚJO} SQ, MATOS MFM, CYRINO EG. Mais Médicos: um programa brasileiro em uma perspectiva internacional. Interface (Botucatu) [online] 2015;(19)54: 623-34. [Acesso em 29 Dez 2015] Disponível em:http://www.scielo.br/pdf/icse/v19n54/1807-5762-icse-19-54-0623.pdf

6. BRASIL. IPEA Instituto de Pesquisa Econômica Aplicada. Perspectivas Profissionais nível médio e superior. Radar; Tecnologia, Produção e Comércio Exterior. Brasília: IPEA; 2011; p. 21.[ Acesso em 29 Dez 2015] Disponível em: http://www.ipea.gov.br/portal/images/stories/PDFs/ radar/130703_radar27.pdf

7. COSER JC. Novos prefeitos e a falta de médicos no país. [Acesso em 29 Dez 2015]. Disponível em: http://cadeomedico.blogspot.com.br/p/deu-na-midia.html

8. SANTOS LMP, SILVA SM. Estudo das Ações Diretas de Inconstitucionalidade do Programa Mais Médicos. Cad. Ibero-Amer. Dir. Sanit., Brasília, v.4, n.1, jan/mar. 2015. [Acesso em 29 Dez 2015]. Disponível em: http://www.cadernos.prodisa.fiocruz.br/index.php/cadernos/article/ viewFile/154/215

9.WHO. World Health Organization.Increasing access to health workers in remote and rural areas through improved retention - Global policy recommendations.Geneva: WHO Press; 2010. [Acesso em 29 Dez 2015] Disponível em: http://apps.who.int/iris/ bitstream/10665/44369/1/9789241564014_eng.pdf

10.HEFCE. Higher Education Funding Council for Wales. Medical and dental students survey 2014 - Survey for the Department of Health and the UK higher education funding bodies. England: Hefce; 2014 [Acesso em 29 Dez 2015] Disponível em: http://www.hefce.ac.uk/media/ hefce/content/pubs/2014/201419/HEFCE2014_19.pdf

11. FRENK J, CHEN L, BHUTTA ZA, COHEN J, CRISP N, EVANS T, FINEBERG H, GARCÍA PJ, KE Y, KELLEY P, KISTNASAMY B, MELEIS A, NAYLOR D, PABLOSMENDEZ A, REDDY S, SCRIMSHAW S, SEPULVEDA J, SERWADDA D, ZURAYK H. Profesionales de lasalud para elnuevosiglo: transformando laeducación para fortalecer los sistemas de saludenun mundo interdependiente. Rev Peru MedExpSalud Publica. 2011; 28(2): 337-41. [Acesso em 29Dez 2015] Disponível em: http://www.scielo.org.pe/pdf/rins/v28n2/ 
a28v28n2.pdf

12. BRASIL. Ministério da Saúde. Secretaria de Gestão do Trabalho e da Educação na Saúde. Programa Mais Médicos - dois anos: mais saúde para os brasileiros.Brasília : Ministério da Saúde, 2015.p. 53-64. [Acesso em 29 Dez 2015] Disponível em: http://cdnmaismedicos. elivepress.com.br/images/PDF/Livro_2_Anos_Mais_Medicos_Ministerio_da_Saude_2015.pdf

13.RISTOFF D. O novo perfil do campus brasileiro: uma análise do perfil socioeconômico do estudante de graduação. Avaliação (Campinas) [online]. 2014, vol.19, n.3, pp. 723-747. [Acesso em 29Dez 2015] Disponível em: http://www.scielo.br/pdf/aval/v19n3/10.pdf

Artigo apresentado em 12-10-15

Artigo aprovado em 29-11-15 Artigo publicado no sistema em 30-12-15 